\title{
Cardiovascular Effects of $\beta$-Carbolines in Conscious Rats
}

\author{
James H. Wible, Friedrich C. Luft, Daniel Stock, and Joseph A. DiMicco
}

\begin{abstract}
The $\beta$-carbolines have a high affinity for the benzodiazepine receptor, where they demonstrate actions opposite to those of the benzodiazepines and elicit anxiogenic effects. We tested the acute cardiovascular effects of $\beta$-carbolines in conscious unrestrained rats. Intravenous infusion of ethyl- $\beta$-carboline-3-carboxylate (BCCE) or methyl- $\beta$-carboline-3-carboxylate (BCCM) caused dose-related decreases in heart rate. Pretreatment with $\mathrm{RO} 15-1788(10.0 \mathrm{mg} / \mathrm{kg}$, i.v.), a benzodiazepine receptor antagonist, or atropine $(1.0 \mathrm{mg} / \mathrm{kg}$, i.v.) prevented the bradycardia elicited by BCCE $(3.0 \mathrm{mg} / \mathrm{kg}$, i.v.). In contrast, tetrahydro- $\beta$-carboline (THBC; $3.0 \mathrm{mg} / \mathrm{kg}$, i.v.) increased both heart rate and blood pressure significantly as compared with controls. However, larger doses of THBC failed to elicit further increases in heart rate or blood pressure. These experiments indicate that in conscious unrestrained rats, $\beta$-carbolines given acutely do not routinely elicit the cardiovascular changes normally associated with stress or anxiety. We next extended our observations to rats given the $\beta$-carboline noreleagnine, $2 \mathrm{mg} / \mathrm{kg}$, or vehicle twice daily intraperitoneally for 4 weeks. The rats were fed either a high salt $(8 \%)$ or a low salt $(0.9 \%)$ diet. At 4 weeks, rats given noreleagnine and high salt had higher tail cuff pressures $(146 \pm 4 \mathrm{vs}$. $134 \pm 4 \mathrm{mmHg}$ ) than those given noreleagnine and low salt. However, with direct arterial measurement, these differences disappeared. These data suggest that $\beta$-carbolines do not provide a useful model for investigating the effects of chronic stress on cardiovascular function in rats. (Hypertens Res 1996; 19: 161-170)
\end{abstract}

Key Words: $\beta$-carbolines, stress, sympathetic nervous system, heart rate, blood pressure, hypertension

The benzodiazepines (BDZ) have established themselves as potent and safe drugs in the treatment of anxiety (1). The association between chronic stress and continuous increases in arterial blood pressure have been established in animal models (2); however, a blood-pressure-lowering effect of BDZ in hypertensive animals or man is less convincing (3). The central nervous system (CNS) contains specific high-affinity-binding sites for BDZtype compounds $(4,5)$. These binding proteins are part of a supramolecular complex that includes a chloride-ion channel, and a receptor for the neurotransmitter $\gamma$-aminobutyric acid (GABA) (6). Interaction of a BDZ with its binding site enhances the action of $G A B A$ at the $\mathrm{GABA}_{\mathrm{A}}$ receptor to increase chloride flux through the chloride ionophore (7).

A second class of compounds, typified by the $\beta$ carbolines, also possess high affinity for BDZ receptors in the CNS $(4,8)$. Unlike the $\mathrm{BDZ}$, the $\beta$-carbolines suppress the action of GABA at the $\mathrm{GABA}_{\mathrm{A}}$ receptor, thereby decreasing chloride conductance (9). The $\beta$-carbolines demonstrate actions opposite to those elicited by the $\mathrm{BDZ}$ in many be- havioral tests $(10-13)$. In conflict paradigms, the $\beta$ carbolines demonstrate proconflict activity $(14,15)$. Since conflict procedures have been widely accepted as good animal models of anxiety (16), the proconflict action of the $\beta$-carbolines suggests that these compounds may be anxiogenic in nature. Consistent with this notion is the finding that FG 7142, a carboxamide $\beta$-carboline, can precipitate attacks of anxiety in man (17). Conflict paradigms have been used to chronically increase blood pressure in mice (2). Whether or not such cardiovascular changes could be elicited by a pharmacologically anxiogenic agent is unknown.

In non-human primates, infusion of ethyl- $\beta$ carboline-3-carboxylate (BCCE) has been reported to elicit both behavioral and physiological changes characteristic of stress and anxiety (18-20). Among the latter effects are increases in heart rate and arterial pressure, which are commonly observed in various paradigms for physical and emotional stress in most mammalian species. All these changes were prevented by pretreatment with RO 15-1788, an agent that blocks the $\mathrm{BDZ}$ receptor-mediated effects of benzodiazepines or $\beta$-carbolines by

From the Departments of Pharmacology, Toxicology, and Medicine, Indiana University School of Medicine, Indianapolis, IN, USA, and Franz Volhard Clinic at the Max Delbrück Center for Molecular Medicine, Humboldt University of Berlin, Berlin, FRG.

Supported by National Institutes of Health Grant NS-19883.

Address for Reprints: Friedrich C. Luft, M.D., Franz Volhard Clinic, Wiltberg Strasse 50, 13122 Berlin, Germany.

Received November 21, 1995; accepted in revised form April 24, 1996. 
occupying their receptor-associated binding sites in vivo and in vitro (21). Consequently, some investigators have suggested that the $\beta$-carbolines may provide a model useful in the study of the pathophysiological effects of anxiety $(22-24)$.

Whereas the anxiogenic activity of the $\beta$-carbolines has been studied primarily in rats, the cardiovascular effects resulting from the acute administration of $\beta$-carbolines have not been reported for this species. Stressors such as inescapable foot shock, air jet, or ultrasound, increase heart rate and arterial pressure in rats (25-27). Similar cardiovascular changes have also been observed in rats subjected to aversive conditioning (28) or conflict paradigms (29). The latter finding is particularly significant because conflict (or punished responding models) have provided the strongest quantifiable and objective behavioral evidence supporting the anxiogenic potential of $\beta$-carbolines.

The purpose of the present investigation was to assess the cardiovascular effects caused by acute and chronic administration of several $\beta$-carbolines in conscious unrestrained rats. We tested ethyl- $\beta$ carboline-3-carboxylate, methyl- $\beta$-carboline-3-carboxylate, tetrahydro- $\beta$-carboline, and noreleagnine. The selections were based on the ability to evoke a stress-like response as well as for reasons of bioavailability. The "pure" antagonist RO 15-1788 was employed to determine the role of benzodiazepine receptors in $\beta$-carboline-induced changes. We reasoned that if the $\beta$-carbolines are to provide a pharmacological model useful in the study of the cardiovascular consequences of stress or anxiety in rats, these agents should evoke cardiovascular changes similar to those seen in other models of stress and anxiety. Our data suggest that the $\beta$-carbolines will not serve as a pharmacological model mimicking the cardiovascular effects of chronic anxiety in experimental animals.

\section{Methods}

\section{General Procedures}

All experiments were performed in conscious male Sprague-Dawley rats (Taconic Laboratory Animals, Germantown, NY, USA) weighing between 300 and $400 \mathrm{~g}$. The animals were housed individually in plastic cages with free access to food and water under controlled temperature, humidity, and light periodicity. The rats were allowed at least 3-4 d for adaptation before catheterization. They were anesthetized with sodium pentobarbital $(50 \mathrm{mg} / \mathrm{kg}$, Abbott Laboratories, Chicago, IL, USA), and femoral arterial and venous catheters, were implanted. The arterial and venous catheter tips were positioned into the abdominal aorta and inferior vena cava, respectively, caudal to the renal vasculature. The catheters were routed subcutaneously to the nape of the neck and then through a small leather harness fastened around the forequarters of each rat. Experimental protocols were performed at least 36-48 $\mathrm{h}$ after catheterization.

On the day of the experiments, the harness on each animal was attached to a spring tether through which an extension of arterial tubing was routed. The other end of the tubing was connected to a water-tight swivel (Instech Laboratories, Plymouth Meeting, PA, USA). Blood pressure was measured with a strain gauge transducer (Statham p23Db). Heart rate was determined with a cardiotachometer (Grass Instruments, Quincy, MA, USA) triggered by the arterial pulse pressure wave. Both heart rate and blood pressure were continuously recorded on a Grass polygraph (Grass Instruments). This system permitted the recording of heart rate and blood pressure in conscious rats moving freely in their home cages. An equilibration period of 45 to 60 min preceded each experimental protocol.

\section{Protocols \\ Experiment 1. Effects of BCCE on heart rate and blood pressure}

Conscious rats were intravenously infused with ethyl- $\beta$-carboline-3-carboxylate (Research Biochemicals Inc., Natick, MA, USA) in increasing doses from 0.1 to $10.0 \mathrm{mg} / \mathrm{kg}$. The different doses of BCCE were infused 45 to $60 \mathrm{~min}$ apart, at which time heart rate and blood pressure had returned to approximately baseline values. All dose were infused in a volume of $1.0 \mathrm{ml} / \mathrm{kg}$.

A stock solution of BCCE was prepared by suspending $10 \mathrm{mg}$ of $\mathrm{BCCE}$ in $1 \mathrm{ml}$ of vehicle A $(200$ $\mathrm{ml}$ of dimethylsulfoxide [DMSO] and 1 drop of Tween 80 brought to a final volume of $1 \mathrm{ml}$ with saline). Subsequent dilutions of the stock solution were made with saline. Animals were treated with vehicle alone on a different day.

Experiment 2. Influence of pretreatment with $R O$ 15-1788 on the cardiovascular response to BCCE

RO 15-1788 (graciously donated by Hoffman La Roche, Basel, Switzerland) was prepared as a fine suspension for intravenous infusion by combining 10 $\mathrm{mg}$ of the drug with $1 \mathrm{ml}$ vehicle B (1 drop DMSO, 1 drop Tween 80 , and $0.9 \mathrm{ml}$ of saline). Animals received an infusion of either RO 15-1788 (10.0 $\mathrm{mg} / \mathrm{kg}$ ) or vehicle $B$ and were treated $10 \mathrm{~min}$ later with either BCCE $(3.0 \mathrm{mg} / \mathrm{kg})$ or vehicle A. All compounds were injected intravenously in a volume of $1.0 \mathrm{ml} / \mathrm{kg}$.

Experiment 3. Influence of pretreatment with atropine on the cardiovascular response to BCCE

Animals were pretreated with either atropine (1.0 $\mathrm{mg} / \mathrm{kg}$; Sigma Chemical Co., St. Louis, MO, USA) or saline. Ten min after pretreatment, rats were infused with BCCE $(3.0 \mathrm{mg} / \mathrm{kg})$. All drugs were infused in a volume of $1.0 \mathrm{ml} / \mathrm{kg}$. BCCE was suspended in vehicle $A$ at a concentration of 3.0 $\mathrm{mg} / \mathrm{ml}$.

Experiment 4. Effects of BCCM on heart rate and blood pressure

Animals were treated with either methyl- $\beta$ carboline-3-carboxylate (BCCM; RBI) or vehicle. BCCM was suspended in vehicle A. All injections were made in volumes of $1.0 \mathrm{ml} / \mathrm{kg}$. 
Experiment 5. Effects of THBC on heart rate and blood pressure

Rats were given increasing doses $(1.0$ to 30.0 $\mathrm{mg} / \mathrm{kg}$ ) of tetrahydro- $\beta$-carboline (THBC; $2,3,4,9$ tetrahydro-1-H-pyrido[3, 4-b]indole; Sigma). Doses of THBC were administered 30 to $45 \mathrm{~min}$ apart, at which time heart rate and blood pressure had returned to approximately baseline levels. A stock solution of THBC $(10.0 \mathrm{mg} / \mathrm{ml})$ was prepared by dissolving THBC in $0.1 \mathrm{~N} \mathrm{HCl}$, titrating back to a $\mathrm{pH}$ of 7.2 with $0.1 \mathrm{~N} \mathrm{NaOH}$, and adding saline to the final volume. Subsequent solutions (1.0 and 3.0 $\mathrm{mg} / \mathrm{ml}$ ) were prepared by diluting the stock solution with saline. All infusions were in a volume of 1.0 $\mathrm{ml} / \mathrm{kg}$ except the THBC dose of $30.0 \mathrm{mg} / \mathrm{kg}$, which was administered in a volume of $3.0 \mathrm{ml} / \mathrm{kg}$. Saline was injected alone in another group of animals.

Experiment 6. Influence of pretreatment with $R O$ 15-1788 on the cardiovascular response to THBC

A group of rats was pretreated with RO 15-1788 $(10.0 \mathrm{mg} / \mathrm{kg}) 10 \mathrm{~min}$ before the infusion of THBC $(3.0 \mathrm{mg} / \mathrm{kg})$. Both compounds were prepared for administration as described previously. Drugs were infused intravenously in a volume of $1.0 \mathrm{ml} / \mathrm{kg}$.

Experiment 7. Effects of THBC on the cardiovascular response to infusion of phenylephrine and isoproterenol i.v.

After a stabilization period, all rats received a bolus infusion of phenylephrine $(10 \mu \mathrm{g})$ and isoproterenol $(10 \mu \mathrm{g})$ in random order, approximately 15 min apart. Upon returning to control heart rate and blood pressure values, animals were treated with either THBC $(3.0$ or $30.0 \mathrm{mg} / \mathrm{kg}$ ) or saline $(1.0$ $\mathrm{ml} / \mathrm{kg}$ ) as described previously. Twenty minutes after treatment, animals again received a bolus infusion of phenylephrine and isoproterenol in random order, about $15 \mathrm{~min}$ apart. Phenylephrine and isoproterenol were obtained from Sigma Chemical Co. and dissolved in saline at a concentration of 100 $\mu \mathrm{g} / \mathrm{ml}$.

Experiment 8. Effects of chronic noreleagnine on heart rate and blood pressure in conscious rats given high- and low-salt diets

Four groups of 12 rats each were tested. Two diets were given. The rats were randomized to either an $8 \%$ high-salt or a $0.9 \%$ (by weight) lowsalt diet. The groups were then given either drug or vehicle. Noreleagnine, $2 \mathrm{mg} / \mathrm{kg}$, or vehicle was given intraperitoneally twice daily for 4 weeks. Blood pressure was measured by tail cuff weekly. After 4 weeks, each rat was anesthetized with sodium pentobarbital and a catheter was placed in the femoral artery and exited at the nape of the neck. The animals were allowed to awaken and their blood pressures were measured directly.

\section{Statistical Analysis}

Results are expressed as mean \pm standard error of the mean (SE). The data were analyzed by analysis of variance (repeated measures as indicated), coupled with a Dunnett's multiple range test and paired

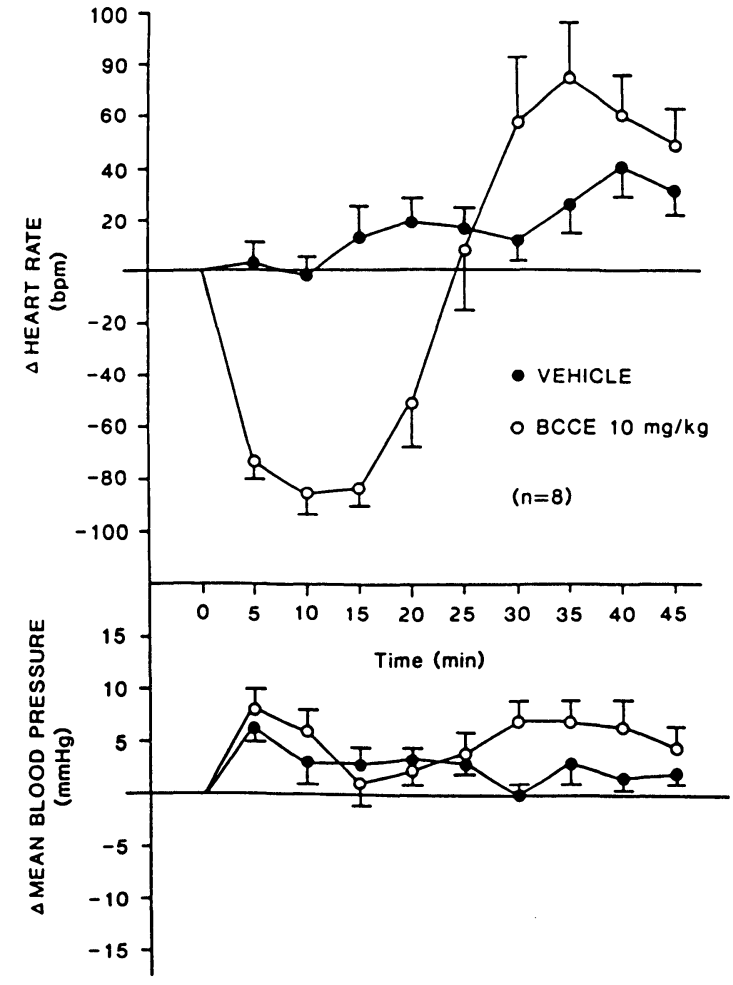

Fig. 1. Time course for changes in heart rate (top) and mean blood pressure (bottom) with respect to baseline after intravenous infusion of either ethyl $\beta$-carboline-3-carboxylate $(B C C E)$ or vehicle in conscious unrestrained rats.

$t$ tests as indicated. Criterion for statistical significance was $p<0.05$.

\section{Results}

Intravenous infusion of BCCE $(10.0 \mathrm{mg} / \mathrm{kg})$ had a biphasic effect on heart rate, characterized by an initial decrease followed by an increase (Fig. 1, top). Baseline heart rate and mean blood pressure before treatment were $380 \pm 5 \mathrm{bpm}$ and $109 \pm 2 \mathrm{mmHg}$, respectively. There were no significant differences in basal heart rate or mean blood pressure between the BCCE and vehicle-treated groups. The peak decrease in heart rate $(-93 \pm 8 \mathrm{bpm})$ occurred $12 \pm 1$ min after infusion of BCCE, whereas the peak increase in heart rate $(86 \pm 16 \mathrm{bpm})$ occurred $36 \pm 2$ min after infusion. Incremental doses of BCCE elicited dose-related decreases in heart rate (Fig. 2, top). Although administration of BCCE increased heart rate, the increase was not statistically different from the increase elicited by infusion of the vehicle (Fig. 1 and Fig. 2, bottom). Similarly, intravenous infusion of BCCE caused a transient increase in mean blood pressure, which was not significantly different from that caused by infusion of the vehicle (Fig. 1, bottom, Fig. 3). Administration of BCCE did not cause any overt change in behavior regardless of the dose infused.

Pretreatment with RO $15-1788(10.0 \mathrm{mg} / \mathrm{kg}) 10$ 


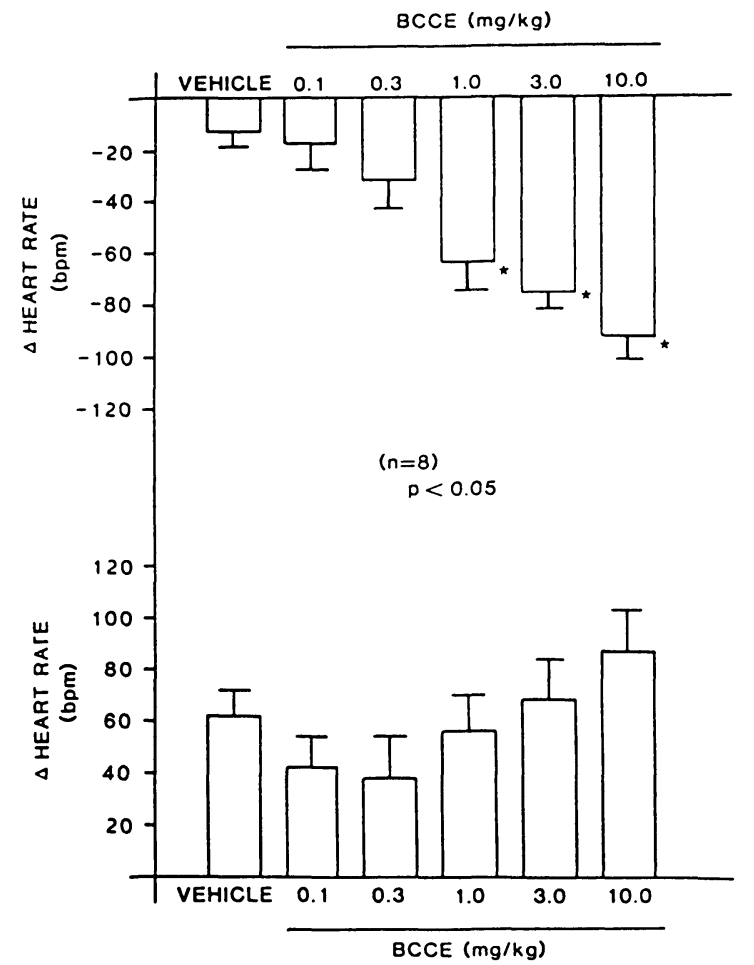

Fig. 2. Mean maximal decrease (top) and increase (bottom) in heart rate after infusion of either vehicle or ethyl$\beta$-carboline-3-carboxylate (BCCE; 0.1-10.0 $\mathrm{mg} / \mathrm{kg}$, i.v.) in conscious rats. Asterisks denote significant difference from vehicle control $(\mathrm{p}<0.05$, by repeated measures $A N O V A$ and Dunnett's test).

min before infusion of BCCE $(3.0 \mathrm{mg} / \mathrm{kg})$ blocked the initial bradycardia elicited by BCCE (Fig. 4, top). Heart rate increased after BCCE administration in animals pretreated with RO 15-1788; however, this increase was not significantly different from the increase in heart rate caused by the vehicle in rats pretreated with RO 15-1788. The transient pressor response elicited either by BCCE or by the vehicle (Fig. 4, bottom) was not affected by pretreatment with RO 15-1788. Administration of RO 15-1788 alone caused no significant change in either heart rate $(395 \pm 12 \mathrm{bpm}$ before, vs. $409 \pm 10 \mathrm{bpm}$ 10 min after infusion) or mean blood pressure (113 $\pm 4 \mathrm{mmHg}$ before, vs. $114 \pm 2 \mathrm{mmHg} 10 \mathrm{~min}$ after administration).

Pretreatment with atropine was employed to examine the role of the vagus nerve in the bradycardia caused by BCCE. Atropine $(1.0 \mathrm{mg} / \mathrm{kg})$ infused $10 \mathrm{~min}$ before administration of BCCE $(3.0 \mathrm{mg} / \mathrm{kg})$ also prevented the decrease in heart rate caused by BCCE (Fig. 5, top). Infusion of atropine significantly increased heart rate from $360 \pm 11 \mathrm{bpm}$ to $460 \pm$ $10 \mathrm{bpm}$, while it had no effect on blood pressure (Fig. 5, bottom).

As with BCCE, intravenous administration of BCCM $(0.5 \mathrm{mg} / \mathrm{kg})$ caused a decrease in heart rate followed by a slow return to baseline (Table 1). However, this dose of BCCM also elicited a pressor

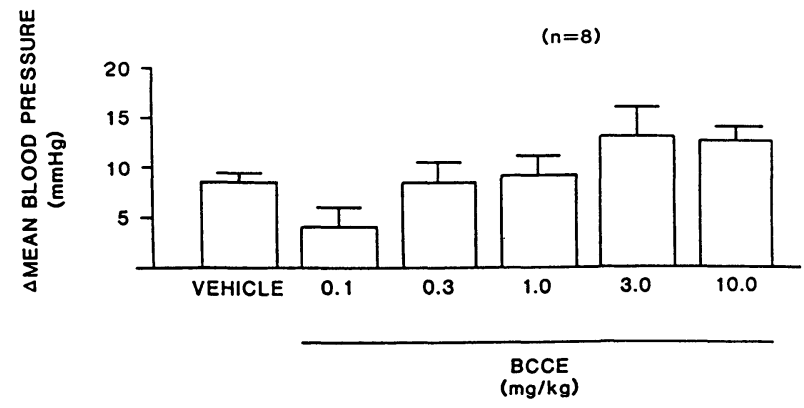

Fig. 3. Peak increase in mean blood pressure after intravenous infusion of either vehicle or ethyl- $\beta$-carboline3-carboxylate (BCCE; 0.1-10.0 $\mathrm{mg} / \mathrm{kg}$ ) in conscious rats.
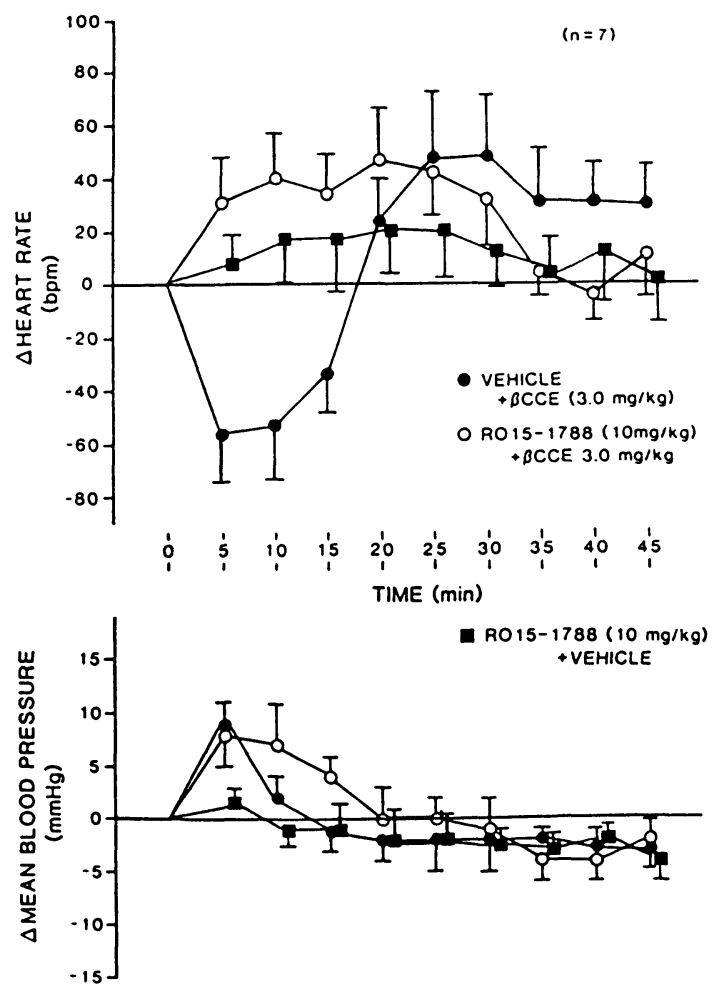

Fig. 4. Mean changes in heart rate (top) and mean blood pressure (bottom) after administration of either vehicle or ethyl- $\beta$-carboline-3-carboxylate (BCCE; $3.0 \mathrm{mg} / \mathrm{kg}$, i.v.). Animals were pretreated with either vehicle or RO 15-1788 (10.0 $\mathrm{mg} / \mathrm{kg}$, i.v.) $10 \mathrm{~min}$ prior to infusion of BCCE or vehicle at time zero.

response, which was significantly larger than that produced by administration of the vehicle, and precipitated a brief convulsion (approximately $1 \mathrm{~s}$ duration). A lower dose of BCCM $(0.1 \mathrm{mg} / \mathrm{kg})$ failed to elicit convulsions but caused a significant decrease in heart rate as compared with baseline. At this lower dose, BCCM caused a transient pressor response. However, the increase in blood pressure did not differ significantly from the increase in blood pressure elicited by the vehicle. 


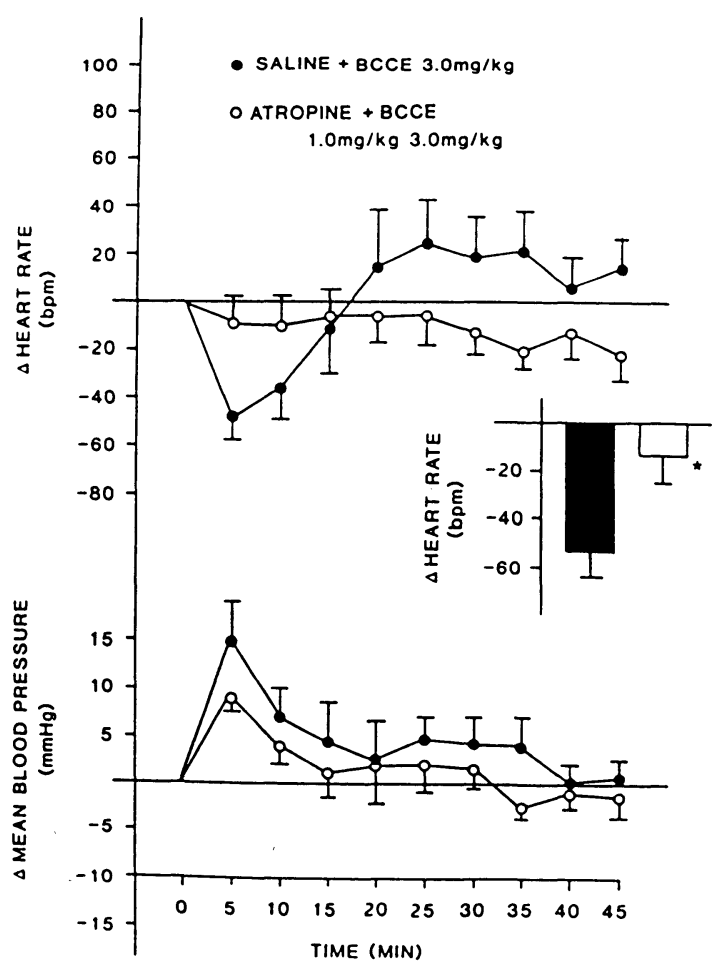

Fig. 5. Mean changes in heart rate (top) and mean blood pressure after intravenous administration of ethyl $\beta$ carboline-3-carboxylate (BCCE; $3.0 \mathrm{mg} / \mathrm{kg})$ in rats pretreated with atropine $(1.0 \mathrm{mg} / \mathrm{kg} ; \mathrm{n}=9)$ or saline $(\mathrm{n}=9)$. Time zero represents the point at which BCCE was administered. Insert depicts the mean. Blood pressure values (bottom) did not differ signficantly between BCCE and $B C C E$ with atropine pretreatment.

Unlike the two previous $\beta$-carbolines, THBC did not produce the biphasic cardiovascular changes seen after administration of BCCE or BCCM. At a dose of $3.0 \mathrm{mg} / \mathrm{kg}$, THBC caused a significant increase in both heart rate and mean blood pressure (Fig. 6 and Table 2). Pretreatment with RO 15-1788, $10 \mathrm{~min}$ before infusion of THBC, prevented the increases in both heart rate and blood pressure elicited by THBC $(3.0 \mathrm{mg} / \mathrm{kg}$; Fig. 6). Higher doses of THBC failed to increase heart rate or blood pressure further. In fact, the higher doses of THBC caused a downward trend in both heart rate and blood pressure. At a dose of $30.0 \mathrm{mg} / \mathrm{kg}$, THBC caused a significant decrease in heart rate (Table 2). This dose of THBC also caused tremors, and the animals assumed a splayed posture. Infusion of THBC at doses higher than $30.0 \mathrm{mg} / \mathrm{kg}$ precipitated convulsions and death.

The downward trend in heart rate and blood pressure after higher doses of THBC suggested that this $\beta$-carboline may interact directly with peripheral $\alpha$ - and $\beta$-adrenoreceptors. Thus, large doses of THBC may mask enhanced autonomic activity evoked by the interaction of this agent with central BDZ receptors. To test this possibility, the cardiovascular effects of phenylephrine $(10 \mathrm{mg})$ and
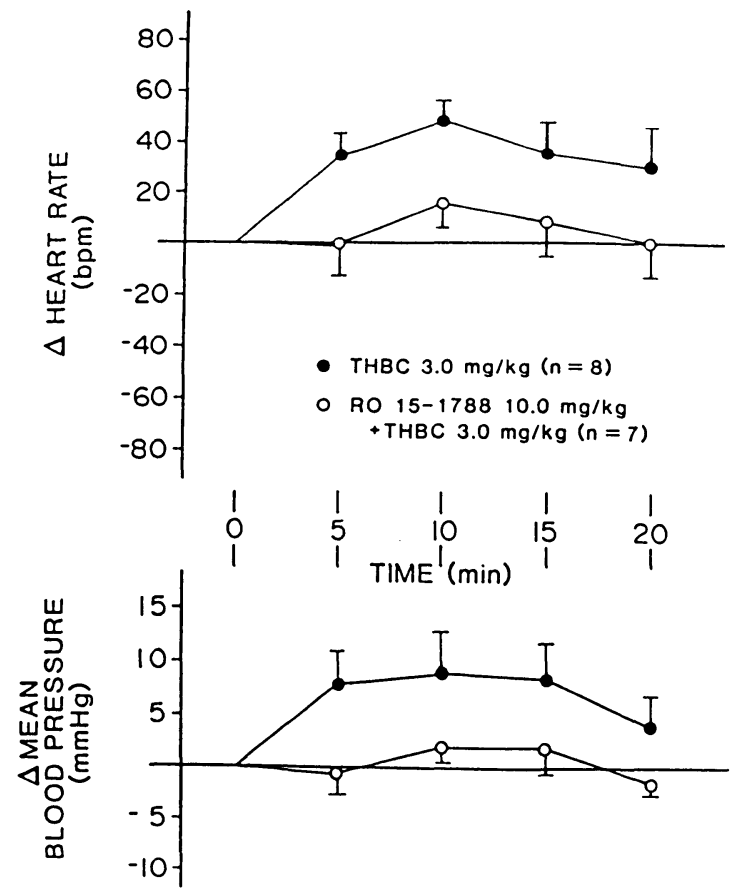

Fig. 6. At a dose of $3.0 \mathrm{mg} / \mathrm{kg}, \mathrm{THBC}$ caused a significant increase in both heart rate and mean blood pressure. Pretreatment with $R O$ 15-1788, 10 min prior to infusion of $T H B C$, prevented the increases in both heart rate and blood pressure elicited by THBC.

isoproterenol $(10 \mathrm{mg})$ were assessed before and after administration of THBC or saline in another group of rats. Administration of THBC (30.0 $\mathrm{mg} / \mathrm{kg}$ ) significantly attentuated the pressor response elicited by phenylephrine and also blunted the tachycardia evoked by isoproterenol (Table 3). Infusion of THBC at a dose of $3.0 \mathrm{mg} / \mathrm{kg}$ or saline did not attenuate or enhance either the pressor response evoked by phenylephrine or the tachycardia produced by isoproterenol.

We next investigated the chronic effects of the $\beta$ carboline noreleagnine on blood pressure. To enhance the chances of observing an effect, we also randomized the treatments with respect to salt content in the diet (Table 4). By 4 weeks, rats given noreleagnine and high salt had higher blood pressure values by tail cuff measurement than the other three groups, which did not differ from one another. However, when the rats had their blood pressures measured directly, no significant differences in arterial blood pressure were observed.

\section{Discussion}

We studied the hemodynamic effects of $\beta$-carbolines in rats both acutely and chronically. We selected BCCE because the drug has been reported to produce cardiovascular changes resembling those seen in fear or anxiety in primates (18). BCCM was selected because of its potency, THBC because of 
Table 1. Peak Changes in Heart Rate and Mean Blood Pressure after Infusion of Either Methyl- $\beta$-Carboline-3-Carboxylate (BCCM) or Vehicle

\begin{tabular}{|c|c|c|c|c|c|c|c|c|}
\hline & $\begin{array}{c}\text { Baseline } \\
\text { Heart Rate } \\
(\mathrm{bpm})\end{array}$ & $\begin{array}{c}\text { Peak Decrease } \\
\text { in Heart Rate } \\
(\mathrm{bpm})\end{array}$ & $\begin{array}{c}\text { Time to } \\
\text { Peak Decrease } \\
\text { (min) }\end{array}$ & $\begin{array}{c}\text { Peak Increase } \\
\text { in Heart Rate } \\
(\mathrm{bpm})\end{array}$ & $\begin{array}{c}\text { Time to } \\
\text { Peak Increase } \\
(\mathrm{min})\end{array}$ & $\begin{array}{c}\text { Baseline } \\
\text { Blood Pressure } \\
(\mathrm{mmHg})\end{array}$ & $\begin{array}{c}\text { Peak Increase } \\
\text { in Blood Pressure } \\
(\mathrm{mmHg})\end{array}$ & $\begin{array}{c}\text { Time to } \\
\text { Peak Increase } \\
(\mathrm{min})\end{array}$ \\
\hline $\begin{array}{l}\text { Vehicle } \\
(1.0 \mathrm{ml} / \mathrm{kg}) \\
\quad(n=8)\end{array}$ & $375 \pm 16$ & $-13 \pm 6$ & $6 \pm 1$ & $+62^{\dagger} \pm 10$ & $39 \pm 2$ & $112 \pm 5$ & $+9^{\dagger} \pm 1$ & $9 \pm 2$ \\
\hline $\begin{array}{l}\text { BCCM } \\
(0.1 \mathrm{mg} / \mathrm{kg}) \\
\quad(n=6)\end{array}$ & $357 \pm 29$ & $-32^{\dagger} \pm 11$ & $5 \pm 1$ & $+62^{\dagger} \pm 16$ & $31 \pm 3$ & $104 \pm 5$ & $+6^{\dagger} \pm 2$ & $4 \pm 1$ \\
\hline $\begin{array}{l}\text { BCCM } \\
(0.5 \mathrm{mg} / \mathrm{kg}) \\
\quad(n=6)\end{array}$ & $378 \pm 15$ & $-68^{* \dagger} \pm 4$ & $7 \pm 1$ & $+22 \pm 12$ & $42 \pm 2$ & $106 \pm 8$ & $+22^{* \dagger} \pm 2$ & $5 \pm 0$ \\
\hline
\end{tabular}

* denotes a significant $(p<0.05)$ difference from vehicle control by ANOVA and Dunnett's test.

${ }^{\dagger}$ indicates a significant $(p<0.05)$ difference from baseline by ANOVA coupled with paired $t$-test.

Table 2. Baseline and Peak Change in Heart Rate and Mean Blood Pressure before and after Intravenous Infusion of Either Tetrahydro- $\beta$-Carboline (THBC) or Saline

\begin{tabular}{|c|c|c|c|c|c|c|c|c|}
\hline & $\begin{array}{c}\text { Baseline } \\
\text { Heart Rate } \\
(\mathrm{bpm})\end{array}$ & $\begin{array}{c}\text { Peak Decrease } \\
\text { in Heart Rate } \\
(\mathrm{bpm})\end{array}$ & $\begin{array}{c}\text { Time to } \\
\text { Peak Decrease } \\
(\mathrm{min})\end{array}$ & $\begin{array}{l}\text { Peak Increase } \\
\text { in Heart Rate } \\
(\mathrm{bpm})\end{array}$ & $\begin{array}{c}\text { Time to } \\
\text { Peak Increase } \\
(\mathrm{min})\end{array}$ & $\begin{array}{c}\text { Baseline } \\
\text { Blood Pressure } \\
(\mathrm{mmHg})\end{array}$ & $\begin{array}{c}\text { Peak Change } \\
\text { in Blood Pressure } \\
(\mathrm{mmHg})\end{array}$ & $\begin{array}{c}\text { Time to } \\
\text { Peak Increase } \\
(\mathrm{min})\end{array}$ \\
\hline $\begin{array}{l}\text { Saline } \\
(1.0 \mathrm{ml} / \mathrm{kg})\end{array}$ & $376 \pm 9$ & $-5 \pm 6$ & $5 \pm 2$ & $+16^{\dagger} \pm 2$ & $12 \pm 2$ & $105 \pm 2$ & $-2 \pm 2$ & $4 \pm 1$ \\
\hline $\begin{array}{l}\text { THBC } \\
(1.0 \mathrm{mg} / \mathrm{kg})\end{array}$ & $393 \pm 15$ & $-9 \pm 4$ & $5 \pm 2$ & $+16^{\dagger} \pm 4$ & $16 \pm 2$ & $104 \pm 4$ & $-2 \pm 4$ & $8 \pm 2$ \\
\hline $\begin{array}{l}\text { THBC } \\
(3.0 \mathrm{mg} / \mathrm{kg})\end{array}$ & $384 \pm 17$ & $-7 \pm 3$ & $1 \pm 1$ & $+59^{* \dagger} \pm 10$ & $12 \pm 1$ & $98 \pm 4$ & $+11^{*+} \pm 4$ & $6 \pm 2$ \\
\hline $\begin{array}{l}\text { THBC } \\
(10.0 \mathrm{mg} / \mathrm{kg})\end{array}$ & $402 \pm 22$ & $-26^{\dagger} \pm 4$ & $4 \pm 1$ & $+25 \pm 12$ & $16 \pm 2$ & $101 \pm 5$ & $-7 \pm 4$ & $18 \pm 2$ \\
\hline $\begin{array}{l}\text { THBC } \\
(30.0 \mathrm{mg} / \mathrm{kg})\end{array}$ & $413 \pm 16$ & $-65^{* \dagger} \pm 23$ & $1 \pm 1$ & $+16 \pm 7$ & $16 \pm 2$ & $95 \pm 4$ & $-13^{\dagger} \pm 4$ & $8 \pm 3$ \\
\hline
\end{tabular}

* denotes a significant $(p<0.05)$ difference from saline control by ANOVA and Dunnett's test.

${ }^{\dagger}$ indicates a significant $(p<0.05)$ difference from baseline by ANOVA coupled with paired $t$-test $(n=8$ in each group).

its solubility in aqueous medium eliminating problems with vehicles, and noreleagnine for pharmacokinetic reasons in the animals treated chronically. We admittedly did not perform detailed behavioral testing in our rats, nor did we measure glucocorticoid levels to assess stress. It is possible that the $\beta$ carboline treated rats were "anxious" in a behavioral sense, but that the cardiovascular components of fear and anxiety were masked by other effects of the $\beta$-carbolines. Possibly, the drugs caused a direct disinhibition of cardiac vagal preganglionic neurons, which in the cat are known to be under tonic GABAergic inhibition (30). Interestingly, and consistent with this notion, is the fact that benzodiazepines are known to be anxiolytic in behavioral tests in the rat and other species, but nevertheless elicit tachycardia through a central vagolytic effect (31).

Systemic administration of $\beta$-carbolines in conscious unrestrained rats did not elicit increases in heart rate and blood pressure normally associated with stress or anxiety in this species. Instead, these agents consistently produced dose-related decreases in heart rate. Pretreatment with RO 15-1788 blocked the bradycardia caused by infusion of BCCE. A central benzodiazepine antagonist, RO 15-1788 displaces both $\mathrm{BDZ}$ and $\beta$-carbolines from the $\mathrm{BDZ}$ receptor in vitro (32) and prevents the in vivo effects of either class of drugs thought to result from their interaction with BDZ receptors. Thus, the decrease in heart rate caused by the $\beta$-carbolines appears to result from an interaction at $\mathrm{BDZ}$ receptors.

Atropine pretreatment also prevented the decrease in heart rate evoked by BCCE, indicating that the $\beta$-carboline affected heart rate by stimulating the cardiac vagus. Earlier work from our laboratory demonstrated that $\mathrm{BDZ}$ are vagolytic in anesthetized rats (31). Therefore, these data support the idea that $\beta$-carbolines have properties opposite to those of the $\mathrm{BDZ}$, as demonstrated in behavioral 
Table 3. Cardiovascular Responses to Phenylephrine and Isoproterenol before and after Tetrahydro- $\beta$-Carboline (THBC) or Saline

\begin{tabular}{|c|c|c|c|c|c|c|c|c|}
\hline & \multicolumn{4}{|c|}{ Phenylephrine $(10 \mu \mathrm{g})$} & \multicolumn{4}{|c|}{ Isoproterenol $(10 \mu \mathrm{g})$} \\
\hline & \multicolumn{2}{|c|}{ Heart Rate (bpm) } & \multicolumn{2}{|c|}{ Blood Pressure (mmHg) } & \multicolumn{2}{|c|}{ Heart Rate (bpm) } & \multicolumn{2}{|c|}{ Blood Pressure (mmHg) } \\
\hline & Baseline & Change & Baseline & Change & Baseline & Change & Baseline & Change \\
\hline \multicolumn{9}{|c|}{ SALINE $(1.0 \mathrm{ml} / \mathrm{kg})$} \\
\hline $\begin{array}{l}\text { Prior to } \\
\text { treatment }\end{array}$ & $362 \pm 10$ & $-178 \pm 33$ & $116 \pm 5$ & $+55 \pm 4$ & $343 \pm 13$ & $+210 \pm 15$ & $109 \pm 6$ & $-38 \pm 3$ \\
\hline $\begin{array}{l}\text { After } \\
\text { treatment }\end{array}$ & $361 \pm 17$ & $-158 \pm 22$ & $112 \pm 6$ & $+50 \pm 4$ & $338 \pm 12$ & $+221 \pm 14$ & $112 \pm 6$ & $-38 \pm 3$ \\
\hline \multicolumn{9}{|c|}{ THBC $(3.0 \mathrm{mg} / \mathrm{kg})$} \\
\hline $\begin{array}{l}\text { Prior to } \\
\text { treatment }\end{array}$ & $342 \pm 9$ & $-142 \pm 19$ & $108 \pm 6$ & $+52 \pm 3$ & $335 \pm 12$ & $+225 \pm 15$ & $110 \pm 6$ & $-39 \pm 4$ \\
\hline $\begin{array}{l}\text { After } \\
\text { treatment }\end{array}$ & $361 \pm 14$ & $-132 \pm 19$ & $111 \pm 6$ & $+52 \pm 3$ & $335 \pm 12$ & $+226 \pm 18$ & $115 \pm 6$ & $-47^{*} \pm 1$ \\
\hline \multicolumn{9}{|c|}{ THBC (30.0 mg/kg) } \\
\hline $\begin{array}{l}\text { Prior to } \\
\text { treatment }\end{array}$ & $470 \pm 12$ & $-156 \pm 12$ & $106 \pm 4$ & $+51 \pm 5$ & $470 \pm 16$ & $+106 \pm 26$ & $99 \pm 3$ & $-37 \pm 3$ \\
\hline $\begin{array}{l}\text { After } \\
\text { treatment }\end{array}$ & $408^{*} \pm 13$ & $-6 * \pm 19$ & $94 \pm 4$ & $+26^{*} \pm 3$ & $406^{*} \pm 12$ & $+58^{*} \pm 13$ & $90 \pm 4$ & $-23 \pm 6$ \\
\hline
\end{tabular}

Table 4. Effects of Noreleagnine (N) and Salt Intake on Blood Pressure in Conscious Rats and Direct Measurement under Anesthesia at Sacrifice (mean \pm SE). Systolic Blood Pressure Measurements Were by Tail Cuff, While Mean Direct Arterial Pressure was Measured by a Catheter in the Femoral Artery.

\begin{tabular}{lcccc}
\hline Regimen & $\begin{array}{c}\text { Control Systolic } \\
(\mathrm{mmHg})\end{array}$ & $\begin{array}{c}2 \text { wk Systolic } \\
(\mathrm{mmHg})\end{array}$ & $\begin{array}{c}4 \text { wk Systolic } \\
(\mathrm{mmHg})\end{array}$ & $\begin{array}{c}4 \text { wk direct Mean } \\
(\mathrm{mmHg})\end{array}$ \\
\hline N/High Salt & $120 \pm 4$ & $139 \pm 3$ & $146 \pm 4^{*}$ & $97 \pm 5$ \\
N/Low Salt & $121 \pm 4$ & $132 \pm 4$ & $134 \pm 4$ & $95 \pm 3$ \\
Ve/High Salt & $122 \pm 3$ & $123 \pm 5$ & $122 \pm 5$ & $92 \pm 4$ \\
Ve/Low Salt & $122 \pm 3$ & $114 \pm 3$ & $121 \pm 4$ & $93 \pm 5$ \\
\hline
\end{tabular}

*Different from all other groups by ANOVA $(p<0.05)$. Ve, Vehicle treatment.

paradigms. Although previous studies in non-human primates had reported that BCCE evokes behavioral and physiological changes indicative of stress and anxiety, in our investigation this agent failed to elicit a similar pattern of cardiovascular changes reportedly associated with stress or anxiety in rats. The transient increase in blood pressure caused by infusion of BCCE in our study was not significantly different from that evoked by the vehicle alone and was unaffected by pretreatment with RO 15-1788. Thus, the increase in blood pressure evoked by infusion of BCCE resulted from a nonspecific action of the vehicle rather than from an interaction of this $\beta$-carboline with $\mathrm{BDZ}$ receptors.

The pressor response also persisted in spite of ganglionic blockade (Wible et al., unpublished observations), suggesting that the increase in blood pressure was not caused by activation of the sympathetic nervous system. While BCCM produced a pressor response significantly greater than that elic- ited by the vehicle, this increase only occurred at doses that precipitated convulsions. Most likely the BCCM-induced seizures caused a generalized activation of the CNS resulting in sympathoadrenal activation, thus accounting for the increase in arterial pressure. Unlike either BCCE or BCCM, THBC elicited cardiovascular changes typical of those associated with anxiety or stress in rats. Infusion of THBC increased heart rate and blood pressure significantly at a dose of $3.0 \mathrm{mg} / \mathrm{kg}$. Since pretreatment with RO 15-1788 attenuated the increases in heart rate and blood pressure, this dose of THBC appears to activate the autonomic nervous system by interacting with $\mathrm{BDZ}$ receptors in the CNS. However, larger doses of THBC failed to produce increases in heart rate or blood pressure that were greater than those caused by saline. This phenomenon could be explained by the apparent ability of THBC to interfere with peripheral adrenoreceptor-mediated responses. 
At a dose of $30.0 \mathrm{mg} / \mathrm{kg}$, THBC lowered basal blood pressure and significantly decreased the pressor response evoked by phenylephrine, an $\alpha$ adrenergic receptor agonist, and attenuated the tachycardia caused by administration of isoproterenol, a $\beta$-adrenergic receptor agonist. Hicks and Langer (33) also found that THBC could antagonize $\alpha$-receptor-mediated vasoconstriction in the rat. Thus, high doses of THBC appear to impair peripheral adrenoreceptor function and may thereby mask the central effects of this $\beta$-carboline to elicit sympathoadrenal stimulation.

The cardiovascular effects of the $\beta$-carbolines seen in our study in rats contrast with the clear pattern of increased heart rate and arterial pressure reported in studies utilizing primates $(18,19,23,34)$. In rhesus monkeys, BCCE was reported to produce increases in heart rate and blood pressure that were dose-related and could be prevented by pretreatment with RO 15-1788. Plasma levels of cortisol, $\mathrm{ACTH}$, epinephrine, and norepinephrine were also increased by $\mathrm{BCCE}$ in these studies. Behavioral changes elicited by BCCE were similar to the changes observed in rhesus monkeys when the animals are threatened or placed in a stressful environment. Therefore, in primates, BCCE appears to produce the behavioral, cardiovascular, and hormonal responses that are characteristic of stress and anxiety.

As noted in this and previous investigations, the $\beta$-carbolines also fail to cause any obvious behavioral effects suggestive of fear or stress in rats $(18,35)$. Since plasma esterases hydrolyze the ester $\beta$-carbolines more rapidly in rats than in primates $(36,37)$, metabolism has been suggested to account for this difference (19). However, the $\beta$-carbolines (including BCCE) elicited BDZ-receptor-mediated cardiovascular changes in rats in the present study. Furthermore, much of the data demonstrating proconflict activity for the $\beta$-carbolines were generated in rats, including a recent report from this laboratory in which BCCE $3 \mathrm{mg} / \mathrm{kg}$ i.p. was shown to intensify punishment-induced suppression of responding (15). Thus, the contention that the $\beta$-carbolines fail to produce overt behavioral effects or cardiovascular changes suggestive of fear or anxiety in rats because of rapid metabolism does not appear to be valid.

We observed some differences in the responses to BCCE, BCCM, and THBC. The modest tachycardia and pressor response produced by THBC was not seen with the other two agents, perhaps because it was masked by a small vehicle effect in the case of BCCE and BCCM. Another possibility is that the profile of dose-related effects of THBC reflects its lower potency, the relative difficulty with which this agent may penetrate the blood-brain barrier, or both, and that lower doses of BCCE or BCCM might have similar, small increases in heart rate without the initial bradycardia. Conversely, higher doses of THBC, at which the peripheral actions would appear to complicate the response, may be necessary to elicit vagal bradycardia. Convulsions were seen only after the highest dose of THBC, while brief convulsions occurred after much lower doses of BCCM. In any event, none of these agents, including THBC, evoked a stress-like response, that is "pure" marked tachycardia, an increase in arterial blood pressure, or both, at any dose.

Several explanations may account for the failure of the $\beta$-carbolines to evoke in rats a predictable pattern of cardiovascular effects resembling those characteristically observed in experimental stress in this species. In rats, the $\beta$-carbolines may elicit a behavioral state analogous to that seen in monkeys and detectable in paradigms such as the conflict test, but unaccompanied by the physiological changes normally associated with anxiety or stress in primates. Different models of stress may produce states characterized by qualitatively different physiological responses in the same species (38). Therefore, it seems feasible that analogous behavioral states evoked by the same stressors may differ in some aspects of their expression among species. Alternatively, the failure of the $\beta$-carbolines to reproduce the physiological changes characteristic of anxiety in rats may cast doubt on the notion that these agents are indeed anxiogenic.

The key experimental evidence supporting their anxiogenic activity derives from the effects of $\beta$-carbolines in punished responding or "conflict" paradigms in laboratory animals. The assumption that pro-conflict effects of $\beta$-carbolines and anti-conflict effects of BDZ represent "anxiogenic" or "anxiolytic" activity of these agents, respectively, has recently been called into question $(39,40)$. A single study by Dorow and colleagues (17) has been extensively cited as definitive proof that the $\beta$-carbolines are anxiogenic in humans. However, in that investigation FG 7142 caused subjects to experience the subjective and physiological symptoms of anxiety on only two occasions, although the drug was administered 12 different times to a total of 5 volunteers. In addition, volunteers were asked to give their informed consent prior to their participation in the trial and thus were aware that they might experience symptoms of anxiety. In the absence of a placebo control, interpretation of the data from that study is, at best, difficult.

In conclusion, administration of $\beta$-carbolines to conscious non-restrained rats at doses previously reported to elicit anxiogenic effects in this species (41) failed to evoke the cardiovascular manifestations typical of stress and anxiety. Instead, systemic administration of BCCE and BCCM caused BDZ receptor-mediated vagal activation, manifest as a decrease in heart rate. Only the water soluble $\beta$ carboline THBC evoked tachycardia and a pressor response; however these cardiovascular effects were not robust. Therefore, the usefulness of the $\beta$-carbolines as a pharmacological tool in studying the acute cardiovascular response to stress and anxiety in the rat is doubtful. We accrued some data on the chronic effects of $\beta$-carbolines on blood-pressure. We observed that tail-cuff blood pressure measurements in rats given BCCE for 4 weeks were greater than in rats receiving placebo; however, a high-salt 
diet was required to elicit this effect. When direct arterial measurements of blood pressure were obtained, these differences could not be substantiated. We cannot exclude residual effects of anesthesia in our rats, since the blood pressure measurements were made within hours rather than days later. Nevertheless, we feel that if a relevant effect on blood pressure was present, we should have been able to detect a blood pressure difference both with indirect and direct measurements. These results are in accord with the report by Quigley et al. (42) who administered the partial inverse $\mathrm{BDZ}$ receptor agonist FG 7142. They found a minimal increase in heart periodicity, but no effect on blood pressure. Taken together, these results suggest that the $\beta$-carbolines are not suitable as a model of stress-induced acute or chronic increases in blood pressure.

\section{References}

1. Greenblatt DJ, Shader RI, Abernethy DR: Current status of benzodiazepines. $N$ Engl J Med 1983; 309: 354-358.

2. Henry JP, Sephens PM, Ely DL: Psychosocial hypertension and the defense and defeat reaction. J Hypertens 1986; 4: 415-424.

3. Freeman ZS. Stress and hypertension - a critical review. Med J Aust 1990; 153: 621-625.

4. Braestrup $C$, Nielsen $M$, Olsen CE: Urinary and brain beta-carboline-3-carboxylates as potent inhibitors of brain benzodiazepine receptors. Proc Natl Acad Sci USA 1980; 77: 2288-2292.

5. Squires RF, Braestrup C: Benzodiazepine receptors in the rat brain. Nature 1977; 266: 732-734

6. Olsen RW: Drug interactions at the GABA receptorionophore complex. Annu Rev Pharmacol Toxicol 1982; 22: 245-277.

7. Richards JG, Mohler H: Benzodiazepine receptors. Neuropharmacology 1984; 23: 233-242.

8. Rommelspacher H, Nanz C, Borbe HO, Fehske KJ, Muller WE, Wollert U: Benzodiazepine antagonism by harmane and other beta-carbolines in vitro and in vivo. Eur J Pharmacol 1981; 70: 409-416.

9. Vicini S, Mienville JM, Costa E: Actions of benzodiazepine and beta-carboline derivatives on gammaaminobutyric acid-activated $\mathrm{Cl}$ channels recorded from membrane patches of neonatal rat cortical neurons in culture. J Pharmacol Exp Ther 1987; 243: 1195-1201.

10. File SE, Lister RG, Nutt DJ: The anxiogenic action of benzodiazepine antagonists. Neuropharmacology 1982; 21: 1033-1037.

11. Petersen EN, Jensen $\mathrm{LH}$, Honore $\mathrm{T}$, et al.: $\mathrm{ZK}$ 91296, a partial agonist at benzodiazepine receptors. Psychopharmacol 1984; 83: 240-248.

12. File SE, Baldwin HA: Effects of beta-carbolines in animal models of anxiety. Brain Res Bull 1987; 19: 293-299.

13. Pellow S, File SE: Multiple sites of action for anxiogenic drugs: behavioral, electrophysiological and biochemical correlations. Psychopharmacol 1984; 83: 304-315.

14. Prado de Carvalho L, Grecksch G, Chapouthier G, Rossier J: Anxiogenic and non-anxiogenic benzodiazepine antagonists. Nature 1983; 301: 64-66.

15. Shekhar A, Hingtgen JN, DiMicco JA: Anxiogenic effects of noreleagnine, a water soluble beta-carboline in rats. Neuropharmcology 1989; 28: 539-542.
16. Geller I: Relative potencies of benzodiazepines as measured by their effects on conflict behavior. Arch Int Pharmacodyn Ther 1964; 149: 243-247.

17. Dorow R, Horowski R, Pascheke G, Amin M, Braestrup C: Severe anxiety induced by FG 7142, a beta-carboline ligand for benzodiazepine receptors. Lancet 1983 ; 1: 98-99.

18. Ninan PT, Insel TM, Cohen RM Skolnick P, Paul SM: Benzodiazepine receptor-mediated experimental "anxiety" in primates. Science 1982; 218: 1332-1334.

19. Insel TR, Ninan PT, Aloi J, Jimerson DC, Skolnick P, Paul SM: A benzodiazepine receptor-mediated model of anxiety. Arch Gen Psychiatry 1984; 41: 741-750

20. Glowa JR, Skolnick P, Paul SM: Effects of betacarboline-3-carboxylic acid ethyl ester on suppressed and non-suppressed responding in the rhesus monkey. Eur J Pharmacol 1986; 129: 39-47.

21. Hunkeler W, Mohler H, Pieri L: Selective antagonists of benzodiazepines. Nature 1981; 290: 514-516.

22. Pellow S, File SE: Anxiolytic and anxiogenic drug effects on exploratory activity in an elevated plusmaze: a novel test of anxiety in the rat. Pharmacol Biochem Behav 1986; 24: 525-529.

23. Skolnick P, Ninan P, Insel T, Crawley J, Paul S: A novel chemically induced animal model of human anxiety. Psychopathology 1984; 17 (Suppl 1): 25-36.

24. Stephens DN and Kehr W: Beta-carbolines can enhance or antagonize the effects of punishment in mice. Psychopharmacol 85: 143-147.

25. McCarty R: Cardiovascular responses to acute foot shock stress in adult and aged Fisher 344 male rats. Neurobiol Aging 1985; 6: 47-50.

26. Kirby RF, Callahan MF, Johnson AK: Regional vascular responses to an acute stressor in spontaneously hypertensive and Wistar-Kyoto rats. $J$ Auton Nerv Syst 1987; 20: 185-188.

27. Julien C, Cerutti C, Kandza P, et al.: Cardiovascular response to emotional stress and spotaneous blood pressure variability in genetically hypertensive rats of the Lyon strain. Clin Exp Pharmacol Physiol 1988; 15: 533-538.

28. Hubbard JW, Cox RH, Sanders BJ, Lawler BJ: Changes in cardiac output and vascular resistance during behavioral stress in the rat. Am J Physiol 1986; 251: R82-R90.

29. Buchholtz RA, Lawler JE, Barker GF: The effects of avoidance and conflict schedules on the blood pressure and heart rate of rats. Physiol Behav 1981; 26: $853-863$

30. DiMicco JA, Gale $\mathrm{K}$, Hamilton $\mathrm{B}$, Gillis RA: GABA receptor control of parasympathetic outflow to heart: characterization and brainstem localization. Science 1979; 204: 1106-1109.

31. DiMicco JA: Evidence for control of cardiac vagal tone by benzodiazepine receptors. Neuropharmacology 1987; 26: 553-559.

32. Möler H, Richards JG: Agonists and antagonist benzodiazepine receptor interaction in vitro. Nature 1981; 294: 763-765.

33. Hicks PE, Langer SZ: Antagonism by tetrahydrobeta-carboline of the vasoconstrictor responses to tryptamine in rat tail arteries. Eur J Pharmacol 1983; 96: $145-149$.

34. Crawley JN, Ninan PT, Pickar D, et al.: Neuropharmacological antagonism of the beta-carboline-induced "anxiety" response in rhesus monkeys. $J$ Neurochem 1985; 5: 477-485.

35. Möler H, Okada T: Benzodiazepine receptors: demonstration in the central nervous system. Science 1977; 198: 849-851. 
36. Mendelson W, Cain M, Cook J, Paul S, Skolnick P: Do benzodiazepine receptors play a role in sleep regulation: studies with the benzodiazepine antagonist, 3-hydroxymethylcarboline (3-HMC). Prog Clin Biol Res 1982; 90: 253-264.

37. Schweri MM, Martin JV, Mendelson WB, Barrett JE, Paul SM, Skoinick P: Pharmacokinetic and pharmacodynamic factors contributing to the convulsant action of beta-carboline-3-carboxylic acid esters. Life Sci 1983; 33: 1505-1512.

38. Paris JM, Lorens SA, Van de Kar LD, Urban JH, Richardson-Morton KD, Bethea CL: A comparison of acute stress paradigms: hormonal responses and hypothalamic serotonin. Physiol Behav 1987; 39: 33-43.

39. Thiebot TH, Soubrie P, Simon P: Is delay of reward mediated by shock avoidance behavior a critical target for anti-punishment effects of diazepam in rats? Psychopharmacol 1985; 87: 473-479.

40. Thiebot MH, Soubrie P, Sanger D: Anxiogenic properties of beta-CCE and FG 7142: a review of promises and pitfalls. Psychopharmacol 1988; 94: 452-463.

41. Stephens DN, Kehr W, Duka T: Anxiolytic and anxiogenic beta-carbolines: tools for the study of anxiety mechanisms. in Biggio G, Costa E (eds): GABAergic Transmission and Anxiety, New York, Raven Press, 1986, pp 91-106.

42. Quigley KS, Sarter MF, Hart SL, Berntson GG: Cardiovascular effects of the benzodiazepine receptor partial inverse agonist FG 7142 in rats. Behav Brain Res 1994; 62: 11-20. 